\title{
Endurance of Renewable Polymer Composite to UV Irradiation
}

\author{
Nik Normunira Mat Hassan ${ }^{1}$, Anika Zafiah Mohd Rus ${ }^{2}$, Fatimah Mohamed Yusop ${ }^{1}$, Noraini Marsi ${ }^{1}$, \\ Nurulsaidatulsyida Sulong ${ }^{3}$, Bachik Abu Bakar ${ }^{1}$, Razlin Abd Rashid ${ }^{1}$, Nor Afzanizam Samiran ${ }^{1}$ \\ ${ }^{1}$ Faculty of Engineering Technology, Universiti Tun Hussein Onn Malaysia, Pagoh Higher Education Hub, 84600 Pagoh, Muar, $\quad$ Jo- \\ hor, Malaysia. \\ ${ }^{2}$ Sustainable Polymer Engineering, Advanced Manufacturing and Material Center (AMMC), University Tun Hussein Onn Malaysia, \\ 86400 Parit Raja, Batu Pahat, Johor, Malaysia. \\ ${ }^{3}$ Faculty of Mechanical Engineering, University Technology MARA (UiTM) Johor Branch, Pasir Gudang Campus, Jalan Purnama, \\ 81750 Masai, Johor, Malaysia \\ *Corresponding author E-mail: normunira@uthm.edu.my
}

\begin{abstract}
Polymer degradation occurs under the influence of sunlight and almost all polymer require stabilization to resist the adverse effect. The polymer degradation leads to discoloration when exposed to ultraviolet (UV) irradiation. In this study the renewable polymer composite was produce by preparation of renewable monomer from waste vegetable oil, crosslink with polymethane polyphenyl isocyanate, distilled water and titanium dioxide $\left(\mathrm{TiO}_{2}\right)$ as filler. The fabrication method of renewable polymer composite in which to produce $\mathrm{RF}$ and its composites (RFC) by manual casting method while for CR and CRC using hot compression moulding technique. The density, porosity and morphology structure of RF, RFC, CR and CRC were measured endurance to UV irradiation exposure for a period of 1000 hours by UV Whetherometer apparatus. The density of RF and RFC exhibit no significant changes after UV irradiation exposure while porosity shows decrease with increasing of percentage of $\mathrm{TiO}_{2}$ filler loading. The morphology structure measurement gives no significant changes of pore cell size of renewable polymer with the increased of filler loading and UV irradiation exposure by different fabrication technique. From observation, discoloration of RF and RFC is less dark as compared to CR and CRC. This is due to the different fabrication technique gives some effects for surface of renewable polymer due to application of heat during hot compression technique. The discoloration surface structure of RF, RFC, CR and CRC were changed from yellow to dark yellow colour after UV irradiation exposure. This is due to formation of quinone structure product produced from the photolysis of renewable polymer under UV irradiation exposure. Hence, $\mathrm{TiO}_{2}$ is used for UV absorber to delay discoloration on the surface of renewable polymer.
\end{abstract}

Keywords: Renewable polymer, Waste vegetable oil, UV irradiation, Discoloration, Morphology structure.

\section{Introduction}

The degradation of polymer is the breakdown of macromolecular owing to heat, oxygen, moisture, light, penetrating radiation, mechanical stresses, biological agents (by action of microorganisms) and other factors. The degradation leads to decrease in the polymer's weight and its structure and physical and chemical properties alter, that is it ages and often becomes unsuitable for practical use [1]. The visible consequences of degradation of polyurethane foams appeared after $20-30$ years of natural degradation [2]. The main visual signs of degradation are discoloration, loss of flexibility and crumbling which is due to influence of moisture, heat and light.

Currently, two common methods used for accelerated UV testing of polymer such as QUV Weatherometer and Xenon Arc Weatherometer. The QUV simulates the effect of sunlight with fluorescent lamps and its simulating rain, dew with constant humidity and the variety of exposure conditions. The advantages of QUV Weatherometer are good screening tool [3]. Furthermore, Xenon Arc Weatherometer is used to simulate the short-wave UV radiation down to $275 \mathrm{~nm}$, which is the most harmful part of the UV spectrum of polymer.

UV absorber were the first protection agents used for polymer. The protection mechanism of UV absorbers is to absorb harmful
UV light and quickly transform it into harmless. The reaction mechanism depends on the agents but common to all, the reaction flow is cyclic. The UV absorber divided into both organic and inorganic. The organic absorber mainly absorbs UV rays while Inorganic UV absorbers are usually certain semiconductor oxides such as $\mathrm{TiO}_{2}, \mathrm{ZnO}, \mathrm{SiO}_{2}$ and $\mathrm{Al}_{2} \mathrm{O}_{3}$. The inorganic $\mathrm{UV}$ agents are more preferred because of their unique features including among others, as nontoxicity, chemical stability at high temperature and permanent stability under UV exposure [4]. UV stabilizer having unique advantages over than organic being non biogenic, no degradable and persist in the environment for a longer time [5].

Titanium dioxide $\left(\mathrm{TiO}_{2}\right)$ act as UV absorber and commonly used to improve the UV protection of coatings and polymer. $\mathrm{TiO}_{2}$ also act as an oxidation catalyst [6]. $\mathrm{TiO}_{2}$ particular is used for its reflective or scattering qualities that prevent UV light from reaching chromophores far below the resin product surface. $\mathrm{TiO}_{2}$ is transform by UV into excited species manage the UV energy they absorb through proton or electron transfer and molecular rearrangement. $\mathrm{TiO}_{2}$ absorber should interact with UV light across the damaging part of the spectrum effectively [7]. 


\section{Methodology}

\subsection{Materials}

Renewable monomer from waste vegetable oil, Polymethane Polyphenyl Isocyanate (Modified Polymeric-MDI) (viscosity at $25^{\circ} \mathrm{C}=$ $120-160 \mathrm{cps}$, specific gravity at $25^{\circ} \mathrm{C}=1.18-1.20 \mathrm{~g} / \mathrm{ml}, \mathrm{NCO}$ Content, wt. $\%=26.3-27.3$ ) and distilled water.

\subsection{Sample Preparations}

Renewable monomer based on waste vegetable oil from Small Medium Entrepreneur (SME's) was prepared by using in-house catalyst preparation to generate the epoxides from unsaturated fatty compound which comprises the acid-catalyst ring opening of the epoxides to form polyols [8,9]. The renewable monomer mixed with Modified Polymeric-MDI was prepared by simple open casting method to produce the renewable polymer foam and hot compression technique to produce the compressed renewable polymer. The mixture was poured into open mould and allowed to rise freely and the renewable polymer foam was removed from the mould after 12 hours. The samples were exposed to the UV light in UV Lamp Test Chamber Model HD-703 (Haida International Equipment Co., LTD) at different exposure time at 250 hours, 500 hours, 750 hours and 1000 hours at $40^{\circ} \mathrm{C}$. The UV exposure of the samples was carried out using an array of UV fluorescent lamps emitting light in the region from 280 to $320 \mathrm{~nm}$ with a tail extending to $400 \mathrm{~nm}$.

\subsection{Density}

The renewable polymer composite samples were tested by PerkinElmer (UK) Spectrum spectrometer at 32 scans with resolution of $4 \mathrm{~cm}^{-1}$ at the wavelength region of $4000-650 \mathrm{~cm}^{-1}$. The CBC samples were cut into $10 \mathrm{~mm} \times 10 \mathrm{~mm} \times 5 \mathrm{~mm}$ to conduct the density test according to ASTM D3575 [10] at various UV irradiation exposure times.

\subsection{Morphology Structure}

The morphology surface structure of each renewable polymer composite sample was sputter coated with gold at $25 \mathrm{~mA}$ plasma current and $2 \mathrm{~Pa}$ of chamber pressure to make them conducting. Cellular structure images were examined by using scanning electron microscope (SEM) of JEOL-JSM6380LAoperating at $15 \mathrm{kV}$ at $30 \mathrm{X}$ magnification.

\section{Results}

3.1. Density and porosity measurements for the renewable polymer and its composite upon exposure to UV irradiation

Physical property of renewable polymer endurance to UV irradiation exposure was determined by density and porosity. The density of RF, CR, RFC and CRC are shown in Figure 1 and Figure 2. Figure 1 shows that the density of RF and RFC exhibited small changed with the increasing percentages of $\mathrm{TiO}_{2}$ filler loading and after UV irradiation exposure up to 1000 hours. The UV irradiation exposure was observed to give very small influenced to the density. This is due to photostability of samples and $\mathrm{TiO}_{2}$ filler successfully act as a stabilizer during UV irradiation exposure. Meanwhile, the highest density of RFC samples with $10 \%$ of $\mathrm{TiO}_{2}$ loading which is $1.1516 \mathrm{~g} / \mathrm{cm}^{3}$ were due to the largest amount of filler loading in the samples. However, the density of RFC samples was linearly increased at all percentage of $\mathrm{TiO}_{2}$ loading and no changes from 0 hour to 1000 hours of UV irradiation exposure.

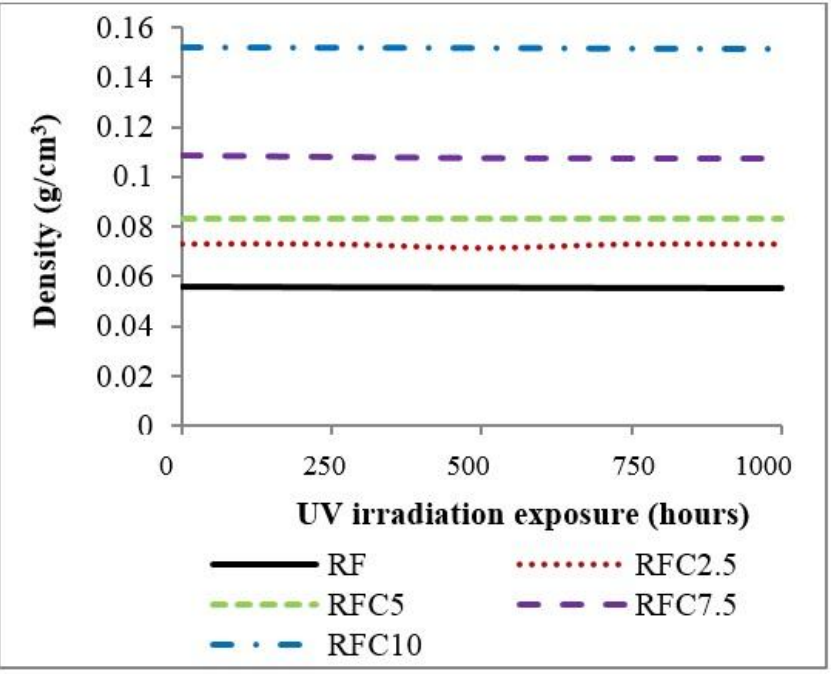

Fig. 1: Density of RF and RFC with different percentage of $\mathrm{TiO}_{2}$ loading before and after UV irradiation exposure

Density of CRC also increased with the increase of percentage of $\mathrm{TiO}_{2}$ filler loading as shown in Figure 2. The UV irradiation exposure of CRC showed very small changes due to stability of $\mathrm{TiO}_{2}$ filler and does not affect the properties of the samples. The density of CR was $0.7838 \mathrm{~g} / \mathrm{cm}^{3}$ before UV irradiation exposure and dropped to $0.7417 \mathrm{~g} / \mathrm{cm}^{3}$ at 250 hours after UV irradiation exposure. This is due to morphological structure of CR shows uniform cell size and small reduction pore sizes during the UV irradiation exposure. The density of all the samples show significant changes with the increasing of $\mathrm{TiO}_{2}$ filler loading but remains constant after UV irradiation exposure up to 1000 hours. This concludes that, $\mathrm{TiO}_{2}$ was acted as a good UV stabilizer to provide photostability properties of the renewable polymer composite.

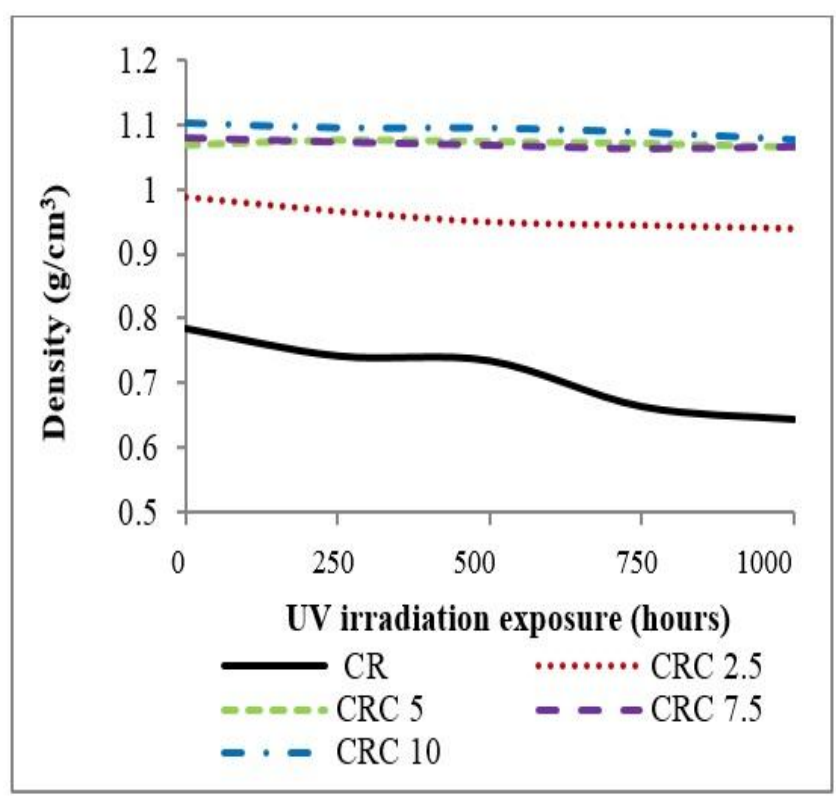

Fig. 2: Density of CR and CRC with different percentage of $\mathrm{TiO}_{2}$ loading before and after UV irradiation exposure

Porosity of RF, CR, RFC and CRC with UV irradiation exposure is shown in Figure 3 and Figure 4 respectively. According to Figure 3, the porosity of RFC shows slight decrease with percentage increase of $\mathrm{TiO}_{2}$ filler loading and UV irradiation exposure. It show that the porosity of RF is 0.14 before UV irradiation exposure and drop to 0.139 at 250 hours UV irradiation exposure. The porosity of CR and CRC show no changes with the increasing of $\mathrm{TiO}_{2}$ filler loading and UV irradiation exposure. This is due to morphological dense structure of $\mathrm{CR}$ and $\mathrm{CRC}$ as examined by SEM which leads to strong bonding of each other. 


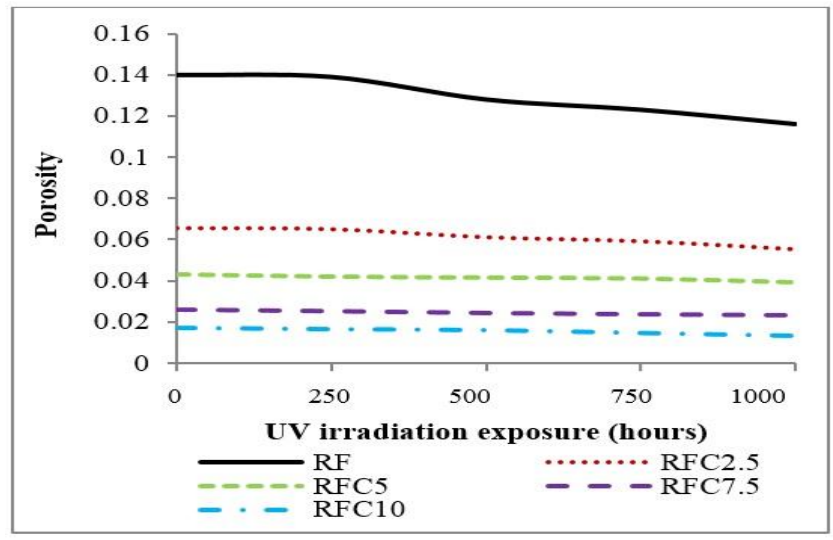

Fig. 3: Porosity of RF and RFC with different percentage of $\mathrm{TiO}_{2}$ loading before and after UV irradiation exposure

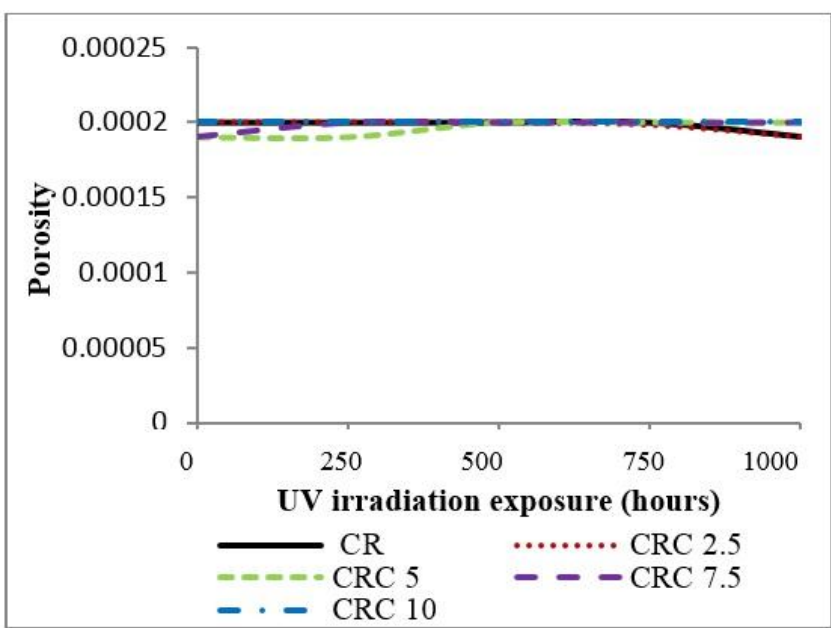

Fig. 4: Porosity of $\mathrm{CR}$ and $\mathrm{CRC}$ with different percentage of $\mathrm{TiO}_{2}$ loading before and after UV irradiation exposure

\subsection{Morphology structure of renewable polymer and its composite of UV irradiation exposure}

The open cell structure of RF and RFC was confirmed by the morphological analysis performed by SEM in Figure 5. The various sizes of open cell in spherical shaped, uniform, cumulative cell size distribution and intrinsic interconnected were recorded with UV irradiation exposure from 0 hours until 1000 hours. The increasing of UV irradiation exposure time has no major effects on RF and RFC cellular structure. This leads to increasing of the vibration and damping characteristic with the increase of UV irradiation exposure due to high cell size of RF and RFC. Moreover, stiffness, density and samples functional group were related to each other and influenced by the morphological structure of samples.

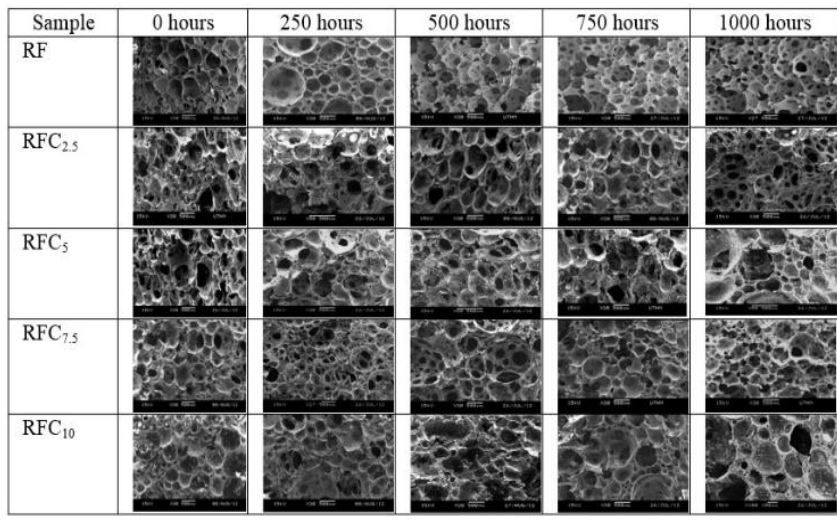

Fig. 5: Surface morphology of RF and RFC before and after UV irradiation exposure
Figure 6 shows the morphological surface and cross sectional structure of CR and CRC with UV irradiation exposure. From the observation, overall structure has no significant changes after UV irradiation exposure. This indicates that $\mathrm{CR}$ and $\mathrm{CRC}$ have high photostability after doped with $\mathrm{TiO}_{2}$ filler loading. Observation on morphological surface section of CRC does not show the location of $\mathrm{TiO}_{2}$ filler loading particle. However, at cross section area, the void and $\mathrm{TiO}_{2}$ filler in CRC samples can be clearly seen. This is due to $\mathrm{TiO}_{2}$ particles located in compressed renewable polymer caused by the deformation of structure during polymerization stages. The void is largest with the highest percentage of $\mathrm{TiO}_{2}$ filler loading but no significant changes after UV irradiation exposure.

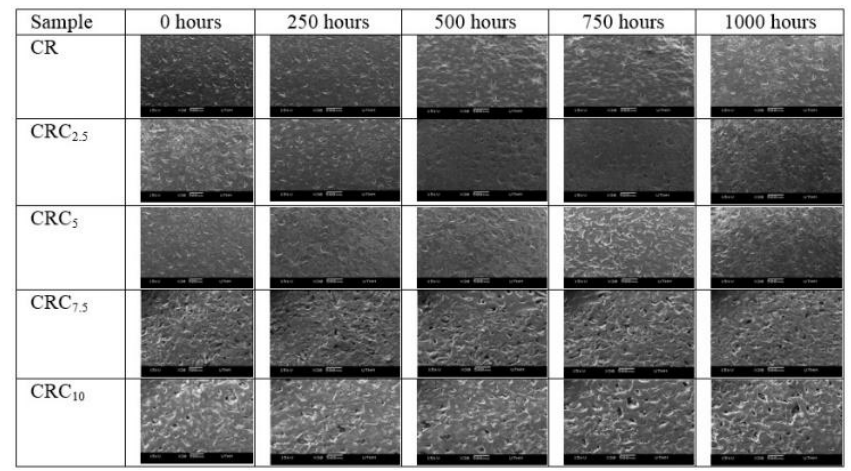

Fig. 6: Surface morphology of CR and CRC before and after UV irradiation exposure

\subsection{Discoloration property of renewable polymer and its composite endurance to UV irradiation exposure}

The discoloration of RF, RFC, CR and CRC were observed based on the colour change at the surface of samples before and after UV irradiation exposure as shown in Figure 7 and Figure 8. The observation from optical microscopy images of RF, CR, RFC and CRC shows significant changes of surface colour from yellow to dark yellow colour after UV irradiation exposure.

Figure 7 shows that RF and RFC turned from pale yellow to darker yellow after UV irradiation exposure from 250 hours to 1000 hours. Furthermore, RF and RFC shows the yellowish colour significantly change with the increase duration of UV irradiation exposure. This is due to the formation of quinone products produced from the photolysis of the polymer. The higher composition of $\mathrm{TiO}_{2}$ loading gives light yellow discolouring of RFC. Ageing of surface samples shows an influence by UV irradiation exposure times and percentages of $\mathrm{TiO}_{2}$ filler loading. The samples turned darker after UV irradiation exposure and less dark with the increasing of $\mathrm{TiO}_{2}$ filler loading.

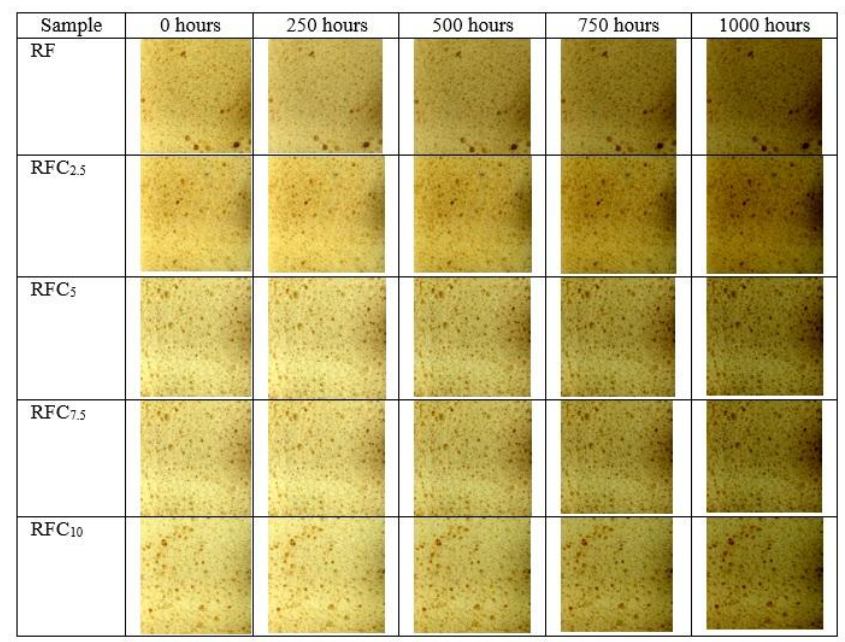

Fig. 7: Yellowish of RF and RFC before and after UV irradiation exposure 
Figure 8 shows both $\mathrm{CR}$ and CRC slowly reduced in colour change due to the increase percentage of $\mathrm{TiO}_{2}$ filler loading after UV irradiation exposure. By increasing the time of UV irradiation exposures will enhance the yellowing performance, thus resulting in decreasing of polymer lifetime [11]. Meanwhile, to increase the polymer lifetime, $\mathrm{TiO}_{2}$ filler loading is used as UV stabilizer and represents the reduction of intensity of carbonyl groups after UV irradiation exposure leads to the reduction of discoloration of RFC and CRC samples.

UV degradation leads to discoloration which is usually shows the reduction of samples property. The discoloration of the samples is due to the formation of quinine structure. The quinine structure was formed when aromatic amine in the sample was oxidized when exposed to UV light and reacting with oxygen. The quinines structure was indicated by the surface of samples getting yellowish. They impart an increasing yellow was due to RF samples as oxidation proceeds over time. Since the quinone is a component of the urethane backbone, the yellow color cannot be extracted from the polymer samples [12].

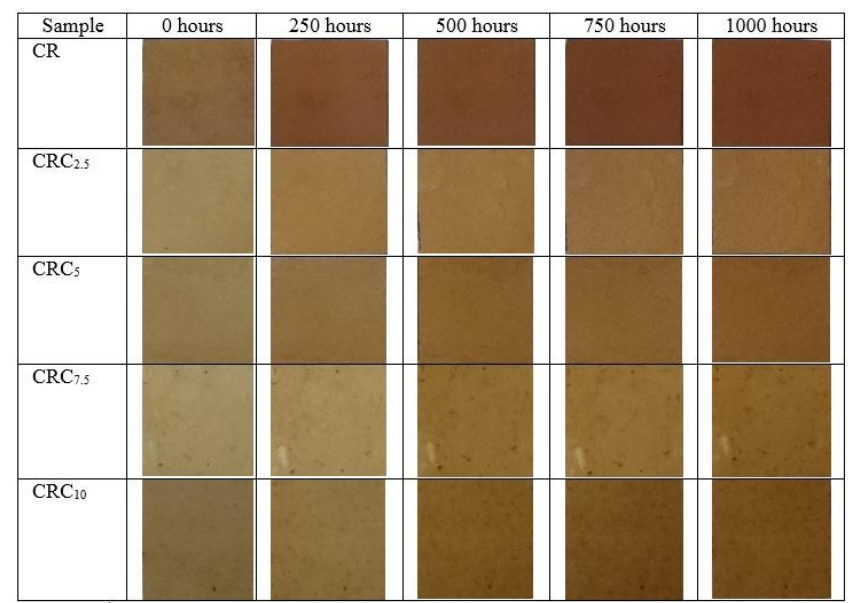

Fig. 8: Yellowish of $\mathrm{CR}$ and $\mathrm{CRC}$ before and after UV irradiation exposure

\section{Conclusion}

This study intendant to contribute to the understanding of renewable polymer with $\mathrm{TiO}_{2}$ filler loading at different fabrication technique in demonstrating the photo stability upon UV irradiation exposure at 1000 hours. The photodegradation of renewable polymer usually starts at the outer surface of the samples of exposed to UV irradiation exposure. The outer surface of CRC was more yellowish compared to RFC due to hot compression technique which gives an effect on the structure of renewable polymer. The yellowish surface leads to formation of quinone structure of renewable polymer after UV irradiation. Meanwhile, in order to prevent the photodegradation of renewable polymer, $\mathrm{TiO}_{2}$ is used as a UV stabilizer to enhance the photosta-bility of renewable polymer. Thus, due to photo stability of RFC at 1000 hours it can be concluded that $\mathrm{TiO}_{2}$ act as UV stabilizer to delay discoloration on the surface of renewable polymer.

\section{Acknowledgement}

The authors would like to thank Universiti Tun Hussein Onn Malaysia (UTHM) for supporting this research study.

\section{References}

[1] Papkov, V.S. "Degradation of Polymer". The Great Soviet Encyclopedia, 3rd Edition. (2010).

[2] Pellizzi E. , Agnes L., Bertrand L. and Herve C. "Degradation of polyurethane ester foam artifacts: Chemical properties, mechanical properties and comparison between accelerated and natural degradation". Polymer Degradation and Stability. Volume 107, 255-261, (2014).

[3] Anika Zafiah M. Rus and Nik Normunira Mat Hassan. "Thermal Degradation and Damping Characteristic of UV irradiated Biopolymer". International Journal of Polymer Science. Volume 2015, Article ID 615284, (2015).

[4] Hongying Y.,1 Sukang Z.,1 and Ning P. "Studying the Mechanisms of Titanium Dioxide as Ultraviolet-Blocking Additive for Films and Fabrics by an Improved Scheme". Journal of Applied Polymer Science, Vol. 92, 3201-3210 (2004).

[5] Sujata Desai and Anuse. "UV stabilization of simazine technical and its formulation by using different packaging materials and inorganic compound TiO2 as UV stabilizer". Applied Science Research, 5 (2):241-250 (2013).

[6] Hyvarinen, M., Vantsi, O., Butylina, and S., Karki, T. "Ultraviolet Light Protection of Wood-Plastic Composites". A Review of the Current Situation. Advanced Science Letters. Vol 9(1), 320-324 (2014).

[7] Michael, T. "Additive for Polyolefins". Published By Elsevier Analytical Chemistry. (2015).

[8] Anika Zafiah M. Rus and Nik Normunira Mat Hassan. "Elastic and damping characteristic of Biopolymer Composite". Applied Mechanics and Materials. Vols. 799-800, pp.187-191. (2015).

[9] S. M. Rus, M. I. Ghazali, and A. Z. M. Rus, "Characteristics of UV irradiated waste biopolymer from renewable resources (Part 2)," Advanced Materials Research, vol. 974, 257-261, (2014).

[10] N. A. Latif and A. Z. M. Rus, "Vibration transmissibility study of high density solid waste biopolymer foam," Journal of Mechanical Engineering and Sciences, vol. 6, 772-781, (2014).

[11] Boubakri, A., Elleuch, K., Guermazi, N., and Ayedi, H.F. "Investigations on Hygrothermal Aging of Thermoplastic Polyurethane Material". Material and Design. Vol 30, 3958-3965, (2009).

[12] Elleder M, and Borovansk J. Auto. "Fluorescence of Melanins Induced by Ultraviolet Radiation and Near Ultraviolet Light. A Histochemical and Biochemical Study". Histochemistry Journal. Vol 33, 273-281. (2001). 